\title{
Pyruvate Carboxylase Deficiency
}

National Cancer Institute

\section{Source}

National Cancer Institute. Pyruvate Carboxylase Deficiency. NCI Thesaurus. Code C85040.

A rare autosomal recessive inherited metabolic disorder caused by mutations in the PC gene. It results in the accumulation of lactic acid and other toxic substances in the blood. Signs and symptoms appear early in life and include failure to thrive, mental and growth retardation, motor disturbances, seizures, and lactic acidosis. 